\title{
PROPHYLAXIS OF PUERPERAL FEVER.*
}

\author{
Bx FRED H. MORISON, M.D., D.P.H.,
}

Medical Officer of Health for West Hartlepool.

IN reading this paper on the "Prophylaxis of Puerperal Fever," I must crave your indulgence, as I do so, not with the hope of laying anything new before this society, but rather with the selfish motive of gaining information, during the discussion, from those members who have had more experience as medical officers of health than myself.

It will be unnecessary to go into all the symptoms, etc., of the disease, because as medical officers of health this does not come within our province.

The mortality from puerperal fever is now somewhat higher in private than in hospital practice. Evidently, then, the conditions under which women are confined outside hospitals have not in an equal degree shared in the improvement undergone by the same conditions in hospital practice.

Such improvement can only be brought about by full appreciation of all that is known of the etiology of the disease, and an adequate sense of responsibility on the part of those brought into contact with the lying-in chamber. The nature of the disease has given rise to much controversy.

The view that it is a specific zymotic disease, such as scarlet fever or small-pox, has been almost universally abandoned, although, I believe, this opinion is still held by some.

The modern view is that it is a specific febrile disturbance analogous to that which may follow surgical wounds, and is due to absorption at some surface. This certainly is my own view of the disease.

With perfect surgical cleanliness, I see no reason at all why cases of midwifery or surgical operations should not with perfect safety be undertaken by those who have recently made post-mortems, or even been employed in dissecting-rooms; and I would say, further, that I see no valid reason for preventing anyone, especially a medical man, who is supposed to know and carry out in all his cases surgical cleanliness, from attending other cases of midwifery because he has been unfortunate enough-or shall I say septic enough ? - to have a case of puerperal fever in his practice.

What surgeon would dream of doing any operation, however trivial, without first taking all the precautions to render every-

* Read at meeting of the Northern Branch, August 2nd, 1901. 
thing aseptic which comes in contact with the wound, and taking every precaution in his power to prevent clothing, etc., coming near? But how many men in attending midwifery cases even take the precaution of doubling up the cuff of their coat, in case of shocking the patient's susceptibilities? Much less do they remove their coats and roll up their sleeves, and yet some men wonder why they have so many cases of puerperal fever.

With midwives, and here is the difficulty, it is a different question. They seldom know what surgical cleanliness is, and have not the knowledge to appreciate the advantages to be gained by it.

Puerperal fever is entirely different from any other of the infectious diseases, because it is only lying-in women who are exposed to the danger of its so-called infection; and this constitutes our great difficulty in guarding against its spread, as no amount of sanitary precautions will have any effect if the disease is, as I believe, conveyed directly by septic hands or clothing of the attendant. And, again, it must not be forgotten that to give a woman puerperal fever it is not necessary for the attendant to have been in contact with a previous case.

That a case of puerperal fever is considered a stigma to a medical man is borne out by the fact that on the notification forms sent in one constantly finds such remarks as "Not attended by me" or "Attended by a midwife," written in red ink by the medical man reporting it.

Having received such a notification, what is our duty? Is it any use telling a midwife that she must not attend any more cases for a given time? I think not. Nor have we power to enforce our instructions.

Or, again, what benefit is derived from disinfecting their clothes, or giving them an antiseptic bath, except that they are for the time being elean? They soon become septic again, and go on infecting nearly every case.

Would it not be better if all midwives were compelled to hold licenses from the local authority of their district? On a case of puerperal fever occurring, the midwife should be warned that if she infect any more women her license will be taken from her. I consider an inquest should be held if the cases prove fatal. This could easily be done if medical men would co-operate and refuse certificates of death.

Much good could also be done by the medical officer of health sending instructions to every midwife in his distriet on the proper method of washing and cleansing the hands, and especially the finger-nails, before making any examinations. 